\title{
O PAPEL DAS REIVINDICAÇÕES SOCIAIS NA GRAMÁTICA DO DIREITO: Uma análise a partir da dogmática jurídica nas demandas de pessoas trans por nome e sexo civis
}

Resumo: O artigo pretende apresentar o papel das reivindicações sociais na gramática do direito a partir da análise da mobilização dos institutos dogmáticos do nome e do sexo civis nas demandas jurídicas por retificação do registro civil de pessoas trans. O objetivo é demonstrar como as lutas sociais, ao expressarem-se na gramática do direito, estruturam disputas sobre os significados dogmáticos de instituições jurídicas e, assim, possibilitam uma avaliação crítica da regulação disponibilizada.

Palavras-chave: Nome civil. Sexo civil. Pessoas trans. Movimentos sociais. Dogmática jurídica.

\section{THE ROLE OF SOCIAL CLAIMS IN LAW GRAMMAR: an analysis based on legal dogmatics in demands of transgender people for civil name and sex}

Abstract: This paper intends to present the role of social demands in law grammar from the analysis of civil name and sex institutes mobilization on legal demands of transgender people. The objective is to demonstrate how social struggles, when expressed in the legal grammar, structure disputes over dogmatic meanings of legal institutions and, thus, make possible a critical evaluation of regulation.

Keywords: Civil name. Civil sex. Transgender people. Social movements. Legal dogmatics.

\section{INTRODUÇÃO}

O artigo pretende apresentar o papel das reivindicações sociais na gramática do direito a partir da análise da mobilização dos institutos do nome e do sexo civis nas demandas jurídicas de pessoas trans. O objetivo é demonstrar como as lutas sociais, ao expressarem-se na gramática jurídica, estruturam disputas sobre os significados dogmáticos de instituições do direito e,

\footnotetext{
* Doutoranda e mestra em Direito pela Universidade do Vale do Rio dos Sinos (PPGD/Unisinos). Bolsista do Programa de Excelência Acadêmica da CAPES (PROEX/CAPES). Bacharela em Ciências Jurídicas e Sociais pela Pontifícia Universidade Católica do Rio Grande do Sul (PUCRS). Ex-integrante do G8-Generalizando. Contato: sschucksilva@gmail.com.
} 
assim, possibilitam uma avaliação crítica da regulação disponibilizada. A análise teórica apresentada neste trabalho é resultado da pesquisa empírica "Fora da norma? Conflitos dogmáticos nas demandas por retificação de nome e sexo no registro civil”, realizada em sede de dissertação de mestrado no período de 2016 a 2017. Na pesquisa, foi elaborado um estudo de caso de caráter quantitativo e qualitativo, e analisadas 167 ações judiciais de retificação de nome e sexo no registro civil de pessoas trans, as quais foram ajuizadas no âmbito do projeto “Direito à Identidade: Viva seu nome!” pelo G8-Generalizando, grupo de direitos sexuais e de gênero do Serviço de Assessoria Jurídica Universitária da Universidade Federal do Rio Grande do Sul (SAJU/UFRGS). Também foram realizadas dezessete entrevistas semiestruturadas com integrantes e ex-integrantes do grupo e com as autoridades judiciárias envolvidas nas demandas. Este artigo é fruto de algumas conclusões resultantes dessa pesquisa.

A escolha da expressão “pessoas trans” para referir as identidades de gênero de mulheres travestis e transexuais, homens transexuais e pessoas transexuais não-binárias decorre das críticas sobre as demarcações fixas de identidades de gênero. Formulações demasiadamente abstratas sobre caracteres identitários frequentemente estão associadas a relações desiguais e assimétricas de poder (HOOKS, 2015; KAAS, 2015; VERGUEIRO, 2016). Também a utilização isolada de alguns termos referentes a identidades sempre pode pôr em prática um processo de desassujeitamento. A expressão “pessoas trans”, portanto, designa primeiramente os sujeitos como pessoas com o objetivo de resumi-los a suas identidades de gênero - assim como ocorre em relação às orientações sexuais, sobre as quais referimos, por exemplo, "mulher lésbica”, "homem bissexual” ou "mulher heterossexual”. A expressão também parece ser menos higienista, como os termos "gay” ou “lésbica” em contraste com "homossexual”. E, por fim, "pessoas trans” resguarda uma justa contraposição com a expressão "pessoas cis”, já utilizada nos movimentos sociais e na escrita científica para referir a identidade de gênero cisgênera. (KAAS, 2015).

O trabalho é divido em três momentos. Na primeira parte, ele apresenta de forma muito breve a trajetória das reivindicações de pessoas trans por alteração do nome e do sexo no registro civil no Brasil. Em um segundo momento, o artigo demonstra a expressão dessas demandas pela gramática jurídica, a partir da análise dogmática das regulações disponibilizadas para nome e sexo no direito brasileiro. Por fim, o trabalho expõe a possibilidade de crítica e avaliação do direito e de suas formas regulatórias em razão das reivindicações de movimentos sociais. 
2 AS REIVINDICAÇÕES DE PESSOAS TRANS POR NOME E SEXO CIVIS

Nos estudos das mobilizações sociais contemporâneas, as reivindicações da sociedade são caracterizadas especialmente por sua ênfase nos processos de construção da identidade. A formação de coletivos com dinâmicas não-lineares, principalmente em relação à negociação ou oposição às práticas e esquemas de compreensão social, é apontada como formato mais comum de coalizão social. Em geral, os debates atuais demonstram como preocupações centrais das lutas sociais a garantia de direitos, a mobilização da opinião pública e a modificação de situações discriminatórias (MCADAM; TARROW, 2009; TILLY, 2010; NIEDERBERGER, 2015). Por fim, além da pluralidade de ideias e valores, as análises indicam uma "busca de reformas institucionais que ampliem o sistema de participação de seus membros no processo de tomada de decisões” (GOHN, 2012, p. 127) como tendência atual dos movimentos. É esse o contexto das lutas de movimentos sociais pela despatologização da transexualidade e da travestilidade, que se tornaram especialmente notórias com a campanha internacional Stop Trans Pathologization, lançada em 2009 com o objetivo de retirar as identidades de gênero das classificações de transtorno mental em catálogos de diagnóstico psiquiátrico (BUNCHAFT, 2016).

No Brasil, apesar da organização geral das reivindicações de lésbicas, gays, bissexuais e pessoas trans iniciarem ainda durante o regime militar, nas décadas de 1960 e 1970, apenas no início da década de 1990 surgem as organizações específicas de travestis (FACCHINI, 2005). A primeira organização política de travestis do Brasil, a Associação das Travestis e Liberados do Rio de Janeiro (ASTRAL), forma-se somente em 1992, no Rio de Janeiro (CARVALHO; CARRARA, 2013). O período é marcado por demandas relacionadas ao combate da violência policial nos locais de prostituição na cidade e ao movimento mais amplo de luta contra o HIV (vírus da imunodeficiência humana) ${ }^{1}$. A identidade de gênero "transexual” só é reivindicada como uma identidade diferente da identidade travesti posteriormente, pelas organizações como o Grupo Brasileiro de Transexuais (GBT), criado em 1995, e o Movimento Transexual de Campinas (MTC), em 1997. Suas pautas apresentam considerável modificação, e as reivindicações passam a focar a reconstrução do discurso médico-psiquiátrico de suas experiências e as demandas de saúde relacionadas à hormonização e às cirurgias de

\footnotetext{
${ }^{1} \mathrm{O}$ preconceito em relação à sua identidade de gênero é frequente causa de abandono familiar. Sem acolhimento também no mercado de trabalho formal, é comum o exercício compulsório de trabalhos socialmente precarizados, como o trabalho sexual (MARTINI; SCHUMANN, 2017).
} 
redesignação sexual ${ }^{2}$. Já os termos “transgênero” e “trans” aparecem no período por influência de pessoas militantes estrangeiras, assim como a expressão “identidade de gênero”, apropriada de estudos médicos pelos movimentos sociais com o objetivo de indicar positivamente sua relação identitária com o gênero (CARVALHO; CARRARA, 2013). Há críticas, no entanto, dos movimentos de travestis às expressões “transexual” e “transgênero”, porque elas entendem ocorrer uma “estratégia de ‘higienização’ do sujeito político do movimento, que estaria assim desvinculado do estigma sexual da prostituição e do escândalo que caracterizariam as travestis” (CARVALHO; CARRARA, 2013, p. 342).

Apesar da permanência de disputas sobre os termos mais adequados para expressar suas identidades de gênero, os movimentos de pessoas trans atualmente convergem sobre os sentidos da travestilidade e da transexualidade como processos de não-identificação com a leitura dimórfica dos corpos, ou seja, com a compreensão binária, permanente (a-histórica) e prédiscursiva (naturalizante) da existência de um corpo masculino e um corpo feminino diferentes e complementáveis (BENTO, 2004; JESUS, 2014; BUTLER, 2015). É nesse sentido sua construção do conceito de cisgeneridade para indicar pessoas cuja identidade de gênero corresponde à leitura dimórfica dos corpos (JESUS; ALVES, 2010; VERGUEIRO, 2016). Em suas reivindicações atuais, estão presentes também a utilização do termo travesti para referir estritamente uma identidade de gênero feminina ${ }^{3}$, a reivindicação de identidades de gênero nãobinárias, ou seja, sem relação necessária com as concepções de feminino e masculino, assim como o emprego da expressão intersexo para referir pessoas cujo corpo não encontra conformação aos termos biomédicos do dimorfismo sexual (JESUS, 2012; ROBERTS; PARKS, 2010; MACHADO, 2005).

As lutas sociais de pessoas trans também impulsionaram os estudos recentes sobre gênero e sexualidade (WALSH; KRABBENDAM, 2017). Na psiquiatria, as pesquisas atuais demonstram que seu sofrimento não está relacionado a uma condição patológica, mas sim resulta da violência e da discriminação social em relação às suas identidades de gênero, o que já era apontado pelos movimentos sociais (ROBLES et al, 2016; REED et al, 2016; MORGAN, 2015; 2016). No Brasil, a questão é explicitada pelos altos índices de homicídio e suicídio da

\footnotetext{
${ }^{2}$ As cirurgias de redesignação sexual ou de transgenitalização consistem em diversos procedimentos médicos de alteração de genitais, mamas e cordas vocais, por exemplo, possíveis de realização por pessoas trans a depender de sua vontade. Atualmente, são reguladas no Brasil pela Portaria $\mathrm{n}^{\circ}$ 2.803, de 19 de novembro de 2013, do Ministério da Saúde (BRASIL, 2013a).

${ }^{3}$ A identidade também é indicada como uma identidade engendrada no Brasil, sem correspondência necessária com o termo transvestite utilizado em outros países (CARVALHO; CARRARA, 2013).
} 
população, especialmente entre as mulheres travestis e transexuais negras (JESUS, 2013; 2014; MARTINI; SCHUMANN, 2017).

Para construir sua inteligibilidade e combater a violência e a discriminação pela sociedade, as pessoas trans lutam atualmente por políticas públicas como a identificação por nome e o sexo em harmonia com suas identidades de gênero. Nas últimas décadas, o país produziu algumas legislações esparsas sobre o nome social, um instituto jurídico criado para acompanhar o nome civil em documentos de identificação oficiais e reduzir os constrangimentos sofridos por portar um nome incondizente com seu próprio reconhecimento (BRASIL, 2013) ${ }^{4}$. Os limites do instituto, porém, foram apontados pelos movimentos social já antes de sua elaboração. Sem a modificação do registro civil, do qual decorrem os principais documentos oficiais de identificação no Brasil, e sem a adoção de normas semelhantes em todos os âmbitos das esferas pública e privada, as demandas se consubstanciaram em processos judiciais para alteração direta do registro no Judiciário (LENTZ, 2013; BENTO, 2014). Não há, contudo, regulação específica para a retificação do registro civil de pessoas trans no país. Esse é o objeto regulatório do Projeto de Lei $\mathrm{n}^{0}$ 5.002, de 20 de fevereiro de 2013, denominado Lei João W. Nery, Lei de Identidade de Gênero, mas ele ainda está em tramitação (WYLLYS; KOKAY, 2013). É necessário compreender, então, como as reivindicações de pessoas trans engendram-se no direito a partir da análise da gramática jurídica disponibilizada para a regulação dos institutos do nome e do sexo civis.

\section{EXPRESSÃO DAS DEMANDAS SOCIAIS PELA GRAMÁTICA DO DIREITO}

A regulação atual dos institutos jurídicos do nome e do sexo civis no direito brasileiro parte de uma terminologia da tradição romano-germânica, em que as situações subjetivas das pessoas eram expressadas no direito pelos seus estados: status libertatis, status civitatis e status familiae. Ainda hoje é comum encontrar nas obras jurídicas referência aos estados da pessoa, mas seus sentidos foram atualizados. O status personae é referido como expressão da posição jurídica individual da pessoa, considerado “uma situação permanente de base, originalmente

\footnotetext{
${ }^{4}$ Como, por exemplo, o Decreto n ${ }^{\circ}$ 8.727, de 28 de abril de 2016, no âmbito da administração pública federal, que compreende como nome social a "designação pela qual a pessoa travesti ou transexual se identifica e é socialmente reconhecida" e como identidade de gênero a "dimensão da identidade de uma pessoa que diz respeito à forma como se relaciona com as representações de masculinidade e feminilidade e como isso se traduz em sua prática social, sem guardar relação necessária com o sexo atribuído no nascimento” (BRASIL, 2016).
} 
adquirida” (PERLINGIERI, 2007, p. 135) pela qual são representadas situações subjetivas relativas à satisfação das necessidades existenciais. O status civitatis é considerado o estado de cidadão de uma organização política estatal, e o status familiae seria a posição do indivíduo nas relações familiares (CUNHA, 2005; SCHREIBER, 2014). De maneira geral, os estados da pessoa, também denominados simplesmente de estados civis, são atributos da personalidade, registram posições ocupadas na vida social e resultam em graduações de capacidade civil. Indicam posições formais da pessoa no interior da gramática do direito em razão do interesse público em distinguir a situação jurídica dos indivíduos nas relações sociais (PERLINGIERI, 2007).

Os estados da pessoa, em tese, representam situações jurídicas modificáveis. Uma pessoa pode adquirir nova nacionalidade (status civitatis) ou mudar seu estado civil de solteira para casada (status familiae), por exemplo. A exceção seria o estado pessoal (status personae) referente ao sexo civil, pois sua regulação jurídica, prevista na Lei de Registros Públicos (Lei $\mathrm{n}^{\circ}$ 6.015, de 31 de dezembro de 1973), disponibiliza os códigos “feminino” ou “masculino”. A determinação de um ou outro código está vinculada à autoridade médica pela Declaração de Nascido Vivo (DNV) no momento do nascimento da pessoa. O estado da pessoa "sexo civil" não se configura, assim, exatamente como um estado, uma situação da pessoa nas relações jurídicas, mas como imposição da autoridade médica com base na anatomia das gônadas, segundo a concepção atual da medicina sobre o seu significado (LOUREIRO, 2014). Em outras palavras, o sexo civil é determinado por autoridade médica e apenas registrado com status jurídico: “Enquanto o médico é aquele que atesta o 'fato' do sexo, o tabelião lhe dá o status jurídico” (SOUSA, 2016, p. 129).

O nome civil, por outro lado, não é considerado um dos estados civis, mas também é referido como atributo da pessoa. Sua regulação não indica posições jurídicas fixas a serem preenchidas, como a regulação do sexo civil, o que permite um espaço maior de autonomia. Porém, há a imposição do registro de um nome no momento do nascimento, o que também revela a ambiguidade de sua regulação. Há uma liberdade para a escolha do nome, mas uma exigência jurídica de sua determinação e de seu registro (PERLINGIERI, 2007; MIRANDA, 2013; SCHREIBER, 2014). O nome também é compreendido pela legislação como imutável, ainda que sua alteração seja possível em razão de algumas exceções legais (BRASIL, 1973; LOUREIRO, 2014). Mesmo sem ser um dos estados da pessoa, o nome civil compartilha com eles uma relação jurídico-regulatória relevante, pois ambos se engendram nos processos de subjetivação das pessoas. Tanto os estados da pessoa quanto o nome civil são institutos jurídicos 


\section{O PAPEL DAS REIVINDICAÇÕES SOCIAIS NA GRAMÁTICA DO DIREITO: uma análise}

a partir da dogmática jurídica nas demandas de pessoas trans por nome e sexo

com o objetivo de personalizar os indivíduos na gramática jurídica, mas suas regulações são exatamente opostas.

Os estados são considerados situações da pessoa, são regulados de forma dinâmica e sua alteração é possibilitada pelo direito. São caracterizados, contudo, por códigos restritivos e prescritivos, pelos quais a pessoa adquire os estados ao cumprir os estritos termos da lei. Por exemplo, a regulação constitucional da nacionalidade e a regulação civil do casamento, cujas normas prescrevem especificamente as condições e os sujeitos passíveis da atribuição dos estados da pessoa "nacional (brasileiro)" e “casado”, excluem casos de refugiados e de casamento entre pessoas do mesmo sexo. Já o nome civil não é considerado uma situação da pessoa, mas confunde-se com sua própria personalidade, como já apontava Pontes de Miranda (1971). Sua modificação é proibida, com estritas exceções, mas sua caracterização é marcada pela autonomia (BRASIL, 1988; 2002; PERLINGIERI, 2007).

Além de contraditórias, porém, as regulações dos atributos da personalidade também são fixas e rigidamente estatais, porque pretendem engendrar o sujeito de direito na gramática jurídica. Pela formalidade do registro civil das pessoas, os sujeitos são individualizados pelo nome e pelos estados civis. Registrado, o sujeito é identificado na sociedade e sua existência é também publicizada e configurada pela gramática jurídica (LOUREIRO, 2014). O sujeito tornase um sujeito de direito. Por isso, há uma dedicação normativa do Estado de Direito para garantir segurança jurídica no processo registral, pois a necessidade de identificação dos sujeitos é imprescindível para a designação individual de direitos e deveres, ou seja, para vincular as pessoas às responsabilidades oriundas de suas relações jurídicas (SCHREIBER, 2014; FACHIN, 2014). Trata-se, portanto, de um procedimento de interesse coletivo, de toda a comunidade cujas relações sociais são regidas pelo direito.

As demandas de pessoas trans, contudo, ao encontrarem pouca possibilidade de expressão pela gramática jurídica disponibilizada, explicitam outro sentido do ato de registrar atributos da personalidade: o registro civil também formula processos identitários. Isso porque os estados e o nome civis envolvem a construção da inteligibilidade da pessoa e a realização e desenvolvimento de sua personalidade (BUTLER, 2017; BROWN, 2002; SCHREIBER, 2014; MIRANDA, 2013). Ao disponibilizar os institutos jurídicos do nome e do sexo, o direito fornece uma gramática para os processos de subjetivação. O nome exerce uma "função essencial na individualização do sujeito e em seu reconhecimento” (FACHIN, 2014, p. 37). A imposição jurídica de identificar-se por um nome e de registrá-lo perante os órgãos oficiais do 
Estado instaura uma interpelação do direito sobre o sujeito, sobre sua identidade (SOUSA, 2016). Essa interpelação provoca e é constituída pelos processos sociais de subjetivação. O nome e todos os demais atributos da personalidade presentes no registro civil não são, assim, apenas caracterizações formais da pessoa relativas somente às suas relações jurídicas, mas exercem uma função importante na própria “construção identitária do ser humano e mesmo em sua qualidade de vida” (FACHIN, 2014, p. 41-42), o que também permite afirmar seu papel imprescindível na “instauração da identidade do sujeito” (FACHIN, 2014, p. 49).

Também já se reconhece a importância do sexo civil nos processos identitários. Sua vinculação permanente à leitura anatômica realizada pela autoridade médica, consoante a previsão da Lei de Registros Públicos, é dirimida atualmente no Judiciário e em obras jurídicas a partir da alegação da existência de um gênero ou "sexo psicossocial” que se sobrepõe, em importância pessoal e social, a um “sexo biológico” (VENTURA, 2007; FACHIN, 2014; DIAS, 2014; CASTRO, 2016). Por isso, já se concebe o sexo civil "não como um estado registral imutável ou como uma verdade superior ao seu titular, mas como um espaço essencial de realização da pessoa humana” (SCHREIBER, 2014, p. 210). Contudo, esse fundamento que diferencia sexo e gênero é baseado na vontade da pessoa, como se o sexo civil, inclusive por ser um instituto disponibilizado pelo próprio direito, não envolvesse processos identitários sociais e intersubjetivos. Mesmo com uma abordagem progressista, ou seja, com o objetivo de ampliar a regulação do sexo civil, essas compreensões falham em fundamentar a possibilidade de sua alteração em “uma esfera de livre atuação e desenvolvimento da pessoa” (SCHREIBER, 2014, p. 210) ou em razão de a dignidade de pessoas trans estar focada em sua "capacidade de autodeterminação e pela possibilidade de criação de uma identidade própria” (FACHIN, 2014, p. 60).

O problema dessas abordagens é, afinal, fixar um (outro) significado jurídico para o sexo civil e impossibilitar as disputas pelo seu sentido oriundas das demandas sociais. Elas desconsideram a relação dos sujeitos de direito com as normas jurídicas e, pela formulação estática de mais um instituto, como, por exemplo, o “sexo psicossocial”, impedem a sociedade de reivindicar suas vivências pelas normas já presentes na gramática jurídica. Formas regulatórias que recaem sobre a identidade e pretendem posicionar os sujeitos em códigos estáticos e pré-determinados são problemáticas por reafirmarem apenas o Estado soberano como lugar competente para sancionar as situações da pessoa nos processos identitários e também por elaborarem modelos jurídicos de subjetivação excludentes (BROWN, 2002; BUTLER, 2003; LANGLEY, 2006; RODRIGUEZ, 2009). 


\section{O PAPEL DAS REIVINDICAÇÕES SOCIAIS NA GRAMÁTICA DO DIREITO: uma análise}

a partir da dogmática jurídica nas demandas de pessoas trans por nome e sexo

O ato de poder reivindicar-se pelo direito parece então ser central para a própria gramática jurídica. Ao disponibilizar uma linguagem pela qual o sujeito pode formular sua identidade, o direito instaura sua própria responsabilidade de tornar essa identidade inteligível pela sua gramática. As reivindicações de pessoas trans, ao mobilizarem institutos do direito, acabam por disputar sua forma de regulação, pois pretendem ampliar o seu significado jurídico. A luta pela ampliação dos sentidos do nome e do sexo no direito pode ser compreendida então como uma disputa jurídico-dogmática, pois refere-se à forma regulatória dos institutos (RODRIGUEZ, 2009; 2013c). Em outras palavras, parece que compreender as demandas de retificação do registro civil de pessoas trans como uma legítima negociação com as regulações dos institutos do nome e do sexo civis oferece indicações do papel das reivindicações sociais para a gramática de direito.

\section{POSSIBILIDADE DE CRÍTICA DO DIREITO A PARTIR DE REIVINDICAÇÕES SOCIAIS}

As reivindicações de pessoas trans pela gramática jurídica parecem ser uma operação de risco: o ingresso no direito já carrega a pretensão de modificá-lo. É preciso analisar então se a própria necessidade de recorrer à gramática jurídica não perturba a possibilidade de o direito dar forma e concretizar reivindicações da sociedade (BROWN, 2002). Qual o sentido e a importância da mobilização do direito pelos movimentos sociais? Em uma releitura da obra de Sófocles, Judith Butler (2014) questionar as origens do parentesco a partir da relação de Antígona com o Estado e analisa o processo de absorção da linguagem estatal contra a qual a personagem se rebela. A partir de sua análise, entende que Antígona “ocupa um espaço de tensão dentro de um sentido ambíguo da lei” (BUTLER, 2014, p. 23). Para a autora, a resistência de Antígona às normas estatais estaria implicada no próprio poder a que ela se opõe e revela assim a ambiguidade e contingência da linguagem do Estado, uma possibilidade de sua disputa e transformação. Ao rejeitar os termos da soberania estatal, Antígona assimila sua linguagem para expressar sua recusa, no sentido de afirmar-se pela voz de quem contesta. Antígona conquista sua autonomia, portanto, “através da apropriação da voz autorizada daquele a quem se resiste, uma apropriação que traz consigo traços de uma simultânea recusa e assimilação dessa própria autoridade” (BUTLER, 2014, p. 30). 
A mobilização da gramática estatal pela personagem sugere que “Antígona não pode fazer sua reinvindicação fora da linguagem do Estado, porém a reivindicação que deseja fazer tampouco pode ser plenamente assimilada por este” (BUTLER, 2014, p. 50). Antígona fala de dentro dos limites legais, é ininteligível pela norma e formula sua existência dentro das normas do Estado para então subverte-las. Com a análise da obra, Judith Butler propõe um exame mais amplo sobre a ambiguidade da mobilização de normas estatais pela sociedade. Na operação, a sociedade aceita e recusa as normas reivindicadas, e as próprias normas são constituídas de forma a possibilitar seu uso mesmo quando ele não é necessariamente concebido pelo Estado. Essa interpretação da autora indica que as normas constituem os sujeitos sem uma inteira possibilidade de escolha, mas também são paradoxalmente o recurso e o repertório para ela: "as normas não são estáticas, elas podem ser transformadas pelos sujeitos a serem formados por elas” (LOIZIDOU, 2007, p. 124, tradução nossa) 5 .

É possível falar, nesse sentido, em uma relação dos sujeitos com as normas sociais. Sempre que a norma não oferece um modo de vida dentro das condições sociais existentes, torna-se impossível ao sujeito apropriá-la sem submetê-la a uma revisão crítica. A própria proposição de universalidade, assim, constrói uma relação com os sujeitos a quem se dirige, uma relação que pressupõe a possibilidade de sua revisão pelas particularidades, em razão do próprio objetivo de sua operação e de sua constituição ocorrer no mesmo contexto das construções das singularidades (BUTLER, 2017; LOIZIDOU, 2007).

Em outras palavras, a afirmação do universal contém em si a responsabilidade de responder a todas as particularidades, ainda que esse processo não seja possível em definitivo. E a própria impossibilidade de acolher todas as particularidades, ou seja, a própria permanência da operação universal, portanto, obriga às normas uma abertura para o particular e perfaz a possibilidade de sua disputa pela sociedade. A interação realizada pela interpelação do universal sobre o particular transforma-o em espaço de questionamento constante, já que ele passa a ser objeto de inquirição contínua sobre seu lugar de enunciação e sobre sua definição ou identidade. Trata-se de um processo relacional e recíproco de responsabilidade entre sujeitos e normas. Quando, por razões sociais, não é possível ao sujeito apropriar-se das normas ou torna-se necessário recusá-las, o preceito converte-se em "um terreno de disputa, tema e objeto do debate democrático” (BUTLER, 2017, p. 17). Significa dizer que é a própria relação com a universalidade que produz a possibilidade de sua discussão: “não há universalidade inteligível,

\footnotetext{
${ }^{5}$ No original, "norms are not static, they can be transformed by the subjects that are to be formed by them".
} 


\section{O PAPEL DAS REIVINDICAÇÕES SOCIAIS NA GRAMÁTICA DO DIREITO: uma análise} a partir da dogmática jurídica nas demandas de pessoas trans por nome e sexo

apenas significados concorrentes de vida e humanidade” (LOIZIDOU, 2007, p. 126, tradução nossa $)^{6}$.

Sem abertura às reivindicações particulares, sem cuidado para com as condições sociais em que ocorre a sua apropriação, a universalidade opera em ilegitimidade. $\mathrm{O}$ universal deve ser entendido, então, como constituído por práticas concretas e substantivas, cujo principal significado político é a compreensão dos sujeitos como agentes dinâmicos e atuantes. Não é possível ao sujeito colocar-se fora das normas sociais, fora de um quadro de inteligibilidade exterior e pré-existente à sua formação. Pelo contrário, os indivíduos utilizam essas normas para sua formação tanto quanto suas particularidades são utilizadas por elas (LANGLEY, 2006; LOIZIDOU, 2007; BUTLER, 2017).

É possível analisar, por essa reflexão, o papel das reivindicações sociais de normas jurídicas. A gramática do direito, ao elaborar uma série de interpelações sobre a identidade dos sujeitos, constrói e disponibiliza uma linguagem com esquemas de inteligibilidade, além de estabelecer uma relação de responsabilidade recíproca. É em relação a esse quadro de referências, sobre como os sujeitos são reconhecíveis pela gramática do direito, que agem as reivindicações sociais. Desde a interpelação, o sujeito enfrenta um processo de produção e reconhecimento de si no interior da linguagem do direito. E a forma da interpelação oferecida pelo direito determina as condições de possibilidade de o sujeito reconhecer-se nessa gramática. Porém, pela análise da obra de Butler, o direito possui uma especificidade no ato de relatar a si mesmo: ele é “o único veículo de resistência e, especificamente, através da prática do julgamento, a única força de dissidência” (LOIZIDOU, 2007, p. 125, tradução nossa)7.

Isso porque integra o próprio processo de legitimação e racionalidade do Estado Democrático de Direito a necessidade de criar as condições para que todos os sujeitos sejam considerados sujeitos de direito em razão de sua promessa de igualdade perante a lei. Em outras palavras, a própria tarefa do direito é possibilitar processos de reconhecimento de si através de sua gramática, ou seja, formular regulações não excludentes, mas inclusivas em relação às diversas realidades sociais e formas de existências (NEUMANN, 2013b; RODRIGUEZ, 2009). E se “a interpelação é o que define o relato que se faz de si mesmo” (BUTLER, 2017, p. 51), as formas da interpelação concentram a principal função da gramática jurídica. Significa considerar a importância das formas regulatórias disponibilizadas na própria legitimação da

\footnotetext{
${ }^{6}$ No original, "there is no intelligible universality, just competing meanings of life and humanness".

${ }^{7}$ No original, "Law, as I explained earlier, becomes for Butler the only vehicle for resistance and, specifically through the practice of the trial, the only force for dissent”.
} 
forma direito, pois a linguagem jurídica interpela os sujeitos por suas instituições e institutos disputados dogmaticamente (RODRIGUEZ, 2015).

O tema está vagamente presente na compreensão de Butler (2017, p. 64-65) de que “julgar o outro é um modo de interpelação" e, nesse sentido, "se existe alguma ética na interpelação, e se o juízo, incluindo o juízo legal, é uma forma de interpelação, então o valor ético do juízo será condicionado pela forma de interpelação que assume”. Sempre que as reivindicações da sociedade mobilizam o direito para elaborar seus processos de identidade, elas compõem suas lutas a partir da gramática disponibilizada pelo direito e disputam, em uma relação crítica, a possibilidade de serem reconhecíveis pelos termos dessa linguagem, ou seja, da linguagem dogmática do direito.

A demanda dos movimentos sociais pelos direitos de pessoas trans desestabilizou a regulação até então consolidada do nome e do sexo e viabilizou o surgimento de novas interpretações jurídicas. A possibilidade de determinada estrutura ou forma regulatória do Estado de Direito mudar de função e ser transformada pela ação de agentes sociais, cuja intervenção ressignifica a dogmática jurídica, fundamenta sua importância para compreender o direito (RENNER, 2010; NEUMANN, 2014). Em razão da função de organizar o material jurídico e possibilitar reflexão sobre ele, a dogmática jurídica tem como principal objetivo limitar democraticamente o poder individual do intérprete na decisão de um caso concreto. É a dogmática jurídica que evita a construção de raciocínios amplamente subjetivos, arbitrários e injustificados pelas instituições jurídicas e possibilita a crítica das decisões do direito pela esfera pública (FERRAZ JÚNIOR, 2015; RODRIGUEZ, 2013d; 2018).

O principal substrato da dogmática jurídica é justamente as demandas elaboradas pela sociedade e expressadas na gramática jurídica. “A dogmática jurídica não é propriedade do poder soberano” (RODRIGUEZ; PÜSCHEL; MACHADO, 2013, p. 45), mas deve ser passível de disputa pela sociedade através da mobilização da gramática jurídica e transformação dos sentidos jurídicos, processo que legitima o direito e fundamenta sua própria racionalidade. Compreender então como movimentos sociais mobilizam o direito para figurar suas lutas e como as instituições jurídicas dão conta de suas reivindicações é analisar justamente os conflitos dogmáticos e tornar possível uma crítica imanente ao direito (RODRIGUEZ, 2009; 2013b; 2015b). As formulações jurídicas devem dar conta das demandas sociais com foco na democratização e na promoção de autonomia, pois as instituições do direito não garantem necessariamente a autonomia da sociedade. Elas devem estar abertas a transformações pela luta social. O direito é racional quando é capaz de acolher as demandas sociais sem destruir sua 


\section{O PAPEL DAS REIVINDICAÇÕES SOCIAIS NA GRAMÁTICA DO DIREITO: uma análise}

a partir da dogmática jurídica nas demandas de pessoas trans por nome e sexo

civis

forma. A forma direito é compreendida aqui como a estrutura de instauração e de garantia da separação entre Estado e sociedade. Ela é necessariamente inclusiva, pois, ao prometer igualdade perante a lei em uma sociedade desigual, possibilita elaborar insatisfações sociais em forma de reivindicações por direitos (NEUMANN, 2013b).

O direito precisa ser pensado em função do conflito social, pela sua possibilidade de expressar ou não as lutas da sociedade. Cada desenho institucional figura as demandas sociais de maneira diferente. É um mecanismo de escuta das insatisfações da sociedade com características específicas, porque determina como a demanda será acolhida e como ela pode ser expressada. Os desenhos institucionais podem ser transformados em função de determinados objetivos da sociedade, e o centro da disputa entre as demandas sociais e as instituições disponibilizadas pelo direito é justamente a dogmática jurídica (NEUMANN, 2013b; RODRIGUEZ, 2009; 2013c; RODRIGUEZ, 2015).

Na sociedade pluralista ocidental contemporânea, há uma grande variação das formas de luta, e não é mais viável a imposição de uma imagem substantiva ou a apresentação de uma solução definitiva para seus conflitos. Parece mais plausível considerar a possibilidade de gestão e reconstrução institucionais constantes em função das contínuas lutas sociais. As reivindicações da sociedade, ao mobilizarem a gramática do direito, revelam assim seu papel procedimental, ou seja, de um mediador democrático dos conflitos sociais para além das diversas visões substanciais de mundo. A partir da existência de uma sociedade ativa, da qual emergem diversificadas reivindicações, o direito é uma das gramáticas pelas quais ela constrói a si mesma e figura suas próprias instituições e práticas (NEUMANN, 2013b). O direito, portanto, “faz parte da definição dos termos em que a sociedade funciona” (RODRIGUEZ, 2009, p. 84).

A potencialidade emancipatória do Estado Democrático de Direito está assinalada justamente em sua promessa de igualdade perante a lei diante de uma sociedade desigual em diversos aspectos. Por sua racionalidade procedimental, o direito legitima-se pela produção de normas em função das demandas da sociedade, porque sua promessa de igualdade, materializada principalmente pela garantia de direitos de liberdade pessoal e de liberdade política, possibilita aos sujeitos relatarem-se como injustiçados e formularem suas insatisfações na forma de reivindicação por direitos (NEUMANN, 2013a). Trata-se de uma promessa que jamais poderá ser plenamente cumprida, mas que permite a constante reivindicação de novos direitos pela sociedade e, como resultado, a efetivação renovada da democracia (RODRIGUEZ, 
2009; 2013a). Deve haver, portanto, transformações efetivadas pela sociedade na gramática jurídica, porque, sem elas, não há legitimidade na função do direito. Porém, essas modificações não podem destruir a forma direito, pois é justamente ela a garantia da possibilidade de mudanças não-violentas, democráticas e continuamente disputáveis. Trata-se da possibilidade de disputar o direito “por dentro”, no interior de sua linguagem (NEUMANN, 2013a; 2014).

De uma forma geral, o direito positivo é exatamente resultado de demandas sociais por igualdade, as quais devem permanecer em constante reformulação, tendo em vista a impossibilidade de satisfação de todas as carências e vontades humanas. Novos problemas jurídicos não cessarão em uma democracia, porque a interpretação firmada em um momento está aberta a reivindicações e a novas formas interpretativas consequentes principalmente de ações judiciais (RODRIGUEZ, 2013a). A forma direito permite uma maneira de subjetivação do mundo, ou seja, a possibilidade de identificar-se como sujeito de direitos. Ao propor uma igualdade impossível, e, portanto, uma universalidade, o direito liberal aponta para além de si e permite a disputa por inclusão em sua gramática, processo pelo qual ele é legitimado perante a sociedade. O sujeito de direitos nasce dessa proposição universal de igualdade, e é a própria possibilidade de reivindicação de si nessa proposição que viabiliza a subjetivação do sujeito na gramática jurídica. O direito exerce assim um papel central na sociedade ocidental, e as reivindicações sociais fundamentam a própria existência da gramática jurídica.

\section{CONSIDERAÇÕES FINAIS}

É necessário um olhar atento para o papel das reivindicações da sociedade para a gramática jurídica e para a importância da dogmática na mobilização do direito pelos movimentos sociais. Semanas após a finalização da pesquisa sobre as ações de retificação do registro civil de pessoas trans, o Supremo Tribunal Federal julgou a Ação Direta de Inconstitucionalidade (ADI) n ${ }^{\circ} 4.275$, proposta pela Procuradoria Geral da República em 2009, cujo objetivo era oferecer interpretação conforme à Constituição à Lei de Registros Públicos e permitir, às pessoas trans, a alteração do nome e do sexo no registro civil sem a realização de cirurgias. Em Repercussão Geral, também foi julgado o Recurso Extraordinário (RE) $n^{0}$ 670.422 do Rio Grande do Sul com a mesma pretensão, além do objetivo de excluir a inserção da palavra "transexual” no campo de averbações do registro de nascimento (BRASIL, 2009; 2012). O julgamento, contudo, acabou por examinar com detalhe a regulação jurídica da retificação do registro civil e, ao final, garantiu às pessoas trans, independentemente de cirurgia 


\section{O PAPEL DAS REIVINDICAÇÕES SOCIAIS NA GRAMÁTICA DO DIREITO: uma análise}

a partir da dogmática jurídica nas demandas de pessoas trans por nome e sexo

de transgenitalização, tratamentos hormonais ou provas patologizantes, o direito à alteração de nome e sexo de forma administrativa diretamente no registro civil. Apesar da conquista fundamental para as pessoas trans, a decisão, ainda não integralmente disponibilizada, parece falhar em alguns aspectos dogmáticos que afetam diretamente a população, como, por exemplo, a impossibilidade de identificação como pessoa não-binária.

Em geral, as identidades não costumam ser objeto de formulação e estudo pela dogmática jurídica, ao passo em que as normas do direito são frequentemente concebidas como necessariamente violentas pelos movimentos sociais. Há pouco ou nenhum esforço compreensivo das reivindicações sociais e das necessidades jurídicas de identificação, pois é comum ao direito e aos movimentos da sociedade compreenderem-se de forma hermética apesar de compartilharem a mesma gramática de regulação nas relações sociais. É justamente nessa situação, no entanto, que o direito se torna fundamental, ou seja, quando existe a separação entre sociedade e Estado e uma tensão entre eles. Com a tensão entre sociedade e Estado, em que as normas jurídicas não são transformadas em meros comandos do poder, é possível a produção das regras jurídicas pela própria sociedade, o que fundamenta e perfaz a racionalidade do direito. A mobilização da gramática jurídica pelos movimentos sociais expõe a própria indeterminação, flexibilidade e ambiguidade das normas jurídicas, mas também é a operação pela qual o direito funda sua legitimidade. Significa compreender a inscrição da possibilidade de inclusão das formas de vida na forma direito, e, de forma imanente, partir dela para considerar outras possibilidades jurídico-regulatórias.

Regular é estabilizar significados jurídicos sem pretendê-los imodificáveis, em razão das próprias características pluralistas da sociedade em que a gramática jurídica opera. A função do direito, assim, está intrinsecamente ligada ao reconhecimento de realidades sociais divergentes reivindicadas pelos sujeitos. O direito é exatamente o lugar democrático possível das reivindicações sociais, portanto, deve manter as condições de possibilidade de um relato de si pela sua gramática. Se o nome e o sexo registrados não servem à identificação do sujeito no direito, eles deixam de operar sua própria função regulatória. Não compete ao direito substancializar as identidades, mas tão somente reconhecer os processos de reivindicação de si demandados pela sociedade. O papel da gramática jurídica é assegurar apenas a própria identificação que instaura, o reconhecimento dos sujeitos como sujeitos de direito.

Se nome e sexo civis são regulações jurídicas pelas quais o direito busca acessar o processo de identificação dos sujeitos, é preciso que elas considerem a relação elaborada pela 
própria gramática jurídica: a relação do sujeito com o direito, pela qual ele ocupa a posição de um sujeito de direitos e estabelece uma relação crítica com suas normas. Ser sujeito de diretos, portanto, é a possibilidade de reivindicar, reiterar, rechaçar e transformar as normas jurídicas, processo pelo qual o próprio direito é legitimado perante a sociedade.

\section{REFERÊNCIAS}

BENTO, Berenice Alves de Melo. Da transexualidade oficial às transexualidades. In: PISCITELLI, Adriana; GREGORI, Maria Filomena; CARRARA, Sérgio. (Org.). Sexualidade e saberes: convenções e fronteiras. Rio de Janeiro: Garamond, 2004, p. 143-172.

BRASIL. Constituição (1988). Constituição da República Federativa do Brasil de 1988. Disponível em: $<$ http://www.planalto.gov.br/ccivil_03/constituicao/constituicaocompilado.htm>. Acesso em: 19 jan. 2018.

BRASIL. Decreto $\mathbf{n}^{\mathbf{0}}$ 8.727, de 28 de abril de 2016. Dispõe sobre o uso do nome social e o reconhecimento da identidade de gênero de pessoas travestis e transexuais no âmbito da administração pública federal direta, autárquica e fundacional. Diário Oficial da União: Brasília, DF, p. 1, 2016. Disponível em: <http://www.planalto.gov.br/ccivil_03/_ato20152018/2016/decreto/D8727.htm>. Acesso em: 19 jan. 2018.

BRASIL. Lei $\mathbf{n}^{\mathbf{0}}$ 10.406, de 10 de janeiro de 2002. Código Civil. Diário Oficial da União: Brasília, DF, $\quad$ p. $1, \quad 2002 . \quad$ Disponível em: $<$ http://www.planalto.gov.br/ccivil_03/leis/2002/L10406compilada.htm>. Acesso em: 29 mar. 2018.

BRASIL. Lei $\mathbf{n}^{\circ} \mathbf{6 . 0 1 5}$, de 31 de dezembro de 1973. Dispõe sobre os registros públicos, e dá outras providências. Diário Oficial da União: Brasília, DF, p. 13528, 1973. Disponível em: <http://www.planalto.gov.br/ccivil_03/leis/L6015compilada.htm>. Acesso em: 29 jan. 2018.

BRASIL. Ministério da Saúde. Gabinete do Ministro. Secretaria de Gestão Estratégica e Participativa Departamento de Apoio à Gestão Participativa. Política nacional de saúde integral de lésbicas, gays, bissexuais, travestis e transexuais. Brasília, DF: 2013. Disponível em <http://bvsms.saude.gov.br/bvs/publicacoes/politica_nacional_saude_lesbicas_gays.pdf $>$. Acesso em: 15 dez. 2017.

BRASIL. Supremo Tribunal Federal. Ação Direta de Inconstitucionalidade $\mathbf{n}^{0} \mathbf{4 2 7 5}$. Requerente: Procuradora-Geral da República. Relator: Ministro Marco Aurélio. Brasília, DF, 26 de janeiro de 2009. Disponível em: $<$ http://www.stf.jus.br/portal/processo/verProcessoAndamento.asp? $\quad$ incidente=2691371 $>$. Acesso em: 16 mar. 2018.

BRASIL. Supremo Tribunal Federal. Recurso extraordinário nº 670.422. Recorrente: S.T.C. Recorrido: Oitava Câmara Cível do Tribunal de Justiça do Estado do Rio Grande do Sul. Relator: Ministro Dias Toffoli. Brasília, DF, 26 de janeiro de 2012. Disponível em: 
<http://www.stf.jus.br/portal/processo/verProcessoAndamento.asp?incidente=4192182>. Acesso em: 16 mar. 2018.

BROWN, Wendy. Suffering the Paradoxes of Rights. In: BROWN, Wendy; HALLEY, Janet (Ed.). Left Legalism/Left Critique. Durham; London: Duke University Press, 2002, p. 420434.

BUNCHAFT, Maria Eugênia. O “direito dos banheiros” no STF: considerações sobre o voto do ministro Luís Roberto Barroso no RE N. 845779 com fundamento em Post, Siegel e Fraser. Constituição, Economia e Desenvolvimento: Revista da Academia Brasileira de Direito Constitucional, Curitiba, v. 8, n. 14, p. 143-174, jan./jun. 2016.

BUTLER, Judith. O clamor de Antígona: parentesco entre a vida e a morte. Florianópolis: UFSC, 2014.

BUTLER, Judith. O parentesco é sempre tido como heterossexual? Cadernos Pagu, São Paulo, n. 21, p. 219-260, 2003.

BUTLER, Judith. Problemas de gênero: feminismo e subversão da identidade. 9. ed. Rio de Janeiro: Civilização Brasileira, 2015.

BUTLER, Judith. Relatar a si mesmo: crítica da violência ética. Belo Horizonte: Autêntica, 2017.

CARVALHO, Mario; CARRARA, Sérgio. Em direção a um futuro trans? Contribuição para a história do movimento de travestis e transexuais no Brasil. Sexualidad, Salud y Sociedad, Rio de Janeiro, n. 14, p. 319-351, ago. 2013.

CASTRO, Cristina Veloso de. As garantias constitucionais das pessoas transexuais. Birigui: Boreal, 2016.

CUNHA, Alexandre dos Santos. A normatividade da pessoa humana: o estatuto jurídico da personalidade e o Código Civil de 2002. Rio de Janeiro: Forense, 2005.

DIAS, Maria Berenice. Homoafetividade e os direitos LGBTI. 6. ed. São Paulo: Revista dos Tribunais, 2014.

FACCHINI, Regina. Sopa de letrinhas? Movimento homossexual e produção de identidades coletivas nos anos 90. Rio de Janeiro: Garamond, 2005.

FACHIN, Luiz Edson. O corpo do registro no registro do corpo: mudança de nome e sexo sem cirurgia de redesignação. Revista Brasileira de Direito Civil, v. 1, p. 36-60, jul./set. 2014.

FERRAZ JÚNIOR, Tércio Sampaio. Função social da dogmática jurídica. 2. ed. São Paulo: Atlas, 2015.

GOHN, Maria da Glória Marcondes. Teorias dos movimentos sociais: paradigmas clássicos e contemporâneos. São Paulo: Loyola, 2012. 
HOOKS, bell. Yearning: Race, Gender, and Cultural Politics. New York: Routledge, 2015.

JESUS, Jaqueline Gomes de; ALVES, Hailey. Feminismo transgênero e movimentos de mulheres transexuais. Revista Cronos, Natal, v. 11, n. 2, nov. 2010.

JESUS, Jaqueline Gomes de. Gênero sem essencialismo: feminismo transgênero como crítica do sexo. Universitas Humanística, Bogotá, n. 78, p. 241-257, jul./dez. 2014.

JESUS, Jaqueline Gomes de. Orientações sobre identidade de gênero: conceitos e termos. Brasília: 2012.

JESUS, Jaqueline Gomes de (Org.). Transfeminismo: teorias e práticas. Rio de Janeiro: Metanoia, 2014.

JESUS, Jaqueline Gomes de. Transfobia e crimes de ódio: Assassinatos de pessoas transgênero como genocídio. História Agora, [S.I.], n. 2, v. 16, p. 101-123, 2013.

KAAS, Hailey. O que é Transfeminismo? Uma Breve Introdução. 2. ed. [S.I.], 2015. Disponível $<$ https://edisciplinas.usp.br/pluginfile.php/371874/mod_resource/content/0/Encontro\%206\%2 0-\%20O-que-\%C3\%A9-Transfeminismo.pdf>. Acesso em: 12 jan. 2018.

LANGLEY, Laura K. Self-determination in a gender fundamentalist state: toward legal liberation of transgender identities. Texas Journal on Civil Liberties \& Civil Rights, Austin, n. 1, v. 12, 2006.

LENTZ, Luísa Helena Stern. Direito à identidade: viva seu nome. A retificação do registro civil como meio de conquista da cidadania para travestis e transexuais. In: Seminário Internacional Fazendo Gênero, 10., 36., 2013, Florianópolis. Anais eletrônicos... Florianópolis: Universidade Federal de Santa Catarina, 2013. Disponível em: <http://www.fg2013.wwc2017.eventos.dype.com.br/resources/anais/20/1373341737_ARQUI VO_FazendoGenero2013TrabalhoCompleto-Final.pdf>. Acesso em: 12 jan. 2018.

LOIZIDOU, Elena. Judith Butler: ethics, law, politics. New York: Routledge-Cavendish, 2007.

LOUREIRO, Luiz Guilherme. Registros púbicos: teoria e prática. 6. ed. Rio de Janeiro: Forense, 2014.

MACHADO, Paula Sandrine. O sexo dos anjos: um olhar sobre a anatomia e a produção do sexo (como se fosse) natural. Cadernos Pagu, n. 24, p. 249-281, jan./jun. 2005

MARTINI, Sandra Regina; SCHUMANN, Berta. Direito e transexualidade: implicações sociais e jurídicas. Porto Alegre: Evangraf, 2017.

MCADAM, Doug; TARROW, Sidney; TILLY, Charles. Para mapear o confronto político. Lua Nova, São Paulo, v. 76, p. 11-48, 2009. 
MIRANDA, Felipe Arady. O direito fundamental ao livre desenvolvimento da personalidade. Revista do Instituto do Direito Brasileiro, Lisboa, a. 2, n. 10, p. 11175-11211, 2013.

MORGAN, Jules. Self-determining legal gender: transgender right, or wrong? The Lancet Diabetes \& Endocrinology, London, v. 4, n. 3, jan. 2016.

MORGAN, Jules. Trans* health: “diversity, not pathology”. The Lancet Psychiatry, London, v. 2, n. 2, fev. 2015.

NEUMANN, Franz. A mudança de função da lei no direito da sociedade burguesa. Revista Brasileira de Estudos Políticos, Belo Horizonte, n. 109, p. 13-83, jul./dez. 2014.

NEUMANN, Franz. O conceito de liberdade política. Cadernos de Filosofia Alemã, São Paulo, n. 22, p. 107-154, 2013a.

NEUMANN, Franz. O império do direito. São Paulo: Quartier Latin, 2013b.

NIEDERBERGER, Andreas. Citizenship, Democracy and the Plurality of Means, Forms and Levels of Participation. In: CELIKATES, Robin; KREIDE, Regina; WESCHE, Tilo (Ed.). Transformations of Democracy. London: Rowman \& Littlefield, 2015. p. 83-106

PERLINGIERI, Pietro. Perfis do direito civil: introdução ao Direito Civil Constitucional. 3. ed. São Paulo: Renovar, 2007.

PONTES DE MIRANDA. Tratado de Direito Privado. Parte Especial. Tomo VI. 3. ed. Rio de Janeiro: Borsoi, 1971.

REED, Geoffrey M. et al. Disorders related to sexuality and gender identity in the ICD-11: revising the ICD-10 classification based on current scientific evidence, best clinical practices, and human rights considerations. World Psychiatry, Geneva, v. 15, n. 3, p. 205-221, out. 2016.

RENNER, Karl. The institutions of private law and their social functions. New Brunswick: Transaction Publishers, 2010.

ROBERTS, Lynne D.; PARKS, Malcolm R. The social geography of gender-switching in virtual environments on the internet. Information, Communication \& Society, London, n. 2, v. 4, p. 521-540, dez. 2010.

ROBLES, Rebeca et al. Removing transgender identity from the classification of mental disorders: a Mexican field study for ICD-11. Lancet Psychiatry, London, jul. 2016.

RODRIGUEZ, José Rodrigo. A desintegração do status quo: direito e lutas sociais. Novos estudos, São Paulo, n. 96, p. 48-66, jul./dez. 2013a.

RODRIGUEZ, José Rodrigo. Como decidem as cortes? Para uma crítica do direito (brasileiro). Rio de Janeiro: FGV, 2013b. 
RODRIGUEZ, José Rodrigo. Dogmática é conflito: a racionalidade jurídica entre sistema e problema. In: RODRIGUEZ, José Rodrigo. PÜSCHEL, Flávia Portela; MACHADO, Marta Rodrigues de Assis. (Org.). Dogmática é conflito: uma visão crítica da racionalidade jurídica. São Paulo: Saraiva, 2013c, p. 21-32.

RODRIGUEZ, José Rodrigo. Fuga do direito: um estudo sobre o direito contemporâneo a partir de Franz Neumann. São Paulo: Saraiva, 2009.

RODRIGUEZ, José Rodrigo. Para uma pedagogia da incerteza: a dogmática jurídica como experimento e como imaginação. In: RODRIGUEZ, José Rodrigo. PÜSCHEL, Flávia Portela; MACHADO, Marta Rodrigues de Assis. (Org.). Dogmática é conflito: uma visão crítica da racionalidade jurídica. São Paulo: Saraiva, 2013d, p. 55-74.

RODRIGUEZ, José Rodrigo; PÜSCHEL, Flávia Portela; MACHADO, Marta Rodrigues de Assis. O raciocínio jurídico-dogmático e suas relações com o funcionamento do poder Judiciário e a democracia. In: RODRIGUEZ, José Rodrigo. PÜSCHEL, Flávia Portela; MACHADO, Marta Rodrigues de Assis. (Org.). Dogmática é conflito: uma visão crítica da racionalidade jurídica. São Paulo: Saraiva, 2013.

RODRIGUEZ, José Rodrigo. Teoria, Sociologia e Dogmática Jurídicas:

Em busca de convergências. In: STRECK, Lenio Luiz; ROCHA, Leonel Severo; ENGELMANN, Wilson. (Org.). Constituição, sistemas sociais e hermenêutica: anuário do Programa de Pós-graduação em Direito da UNISINOS: mestrado e doutorado: n. 16. Porto Alegre: Livraria do Advogado; São Leopoldo: UNISINOS, 2018. No prelo.

RODRIGUEZ, José Rodrigo. “Utopias” institucionais antidiscriminação: as ambiguidades do direito e da política no debate feminista brasileiro. Cadernos Pagu, São Paulo, n. 45, p. 297329, 2015.

SCHREIBER, Anderson. Direitos da personalidade. 3. ed. São Paulo: Atlas, 2014.

SOARES, Tuanny Soeiro. O nome que eu (não) sou: retificação de nome e sexo de pessoas transexuais e travestis no registro civil. Rio de Janeiro: Lumen Juris, 2016.

TILLY, Charles. Movimentos sociais como política. Revista Brasileira de Ciência Política, n. 3. Brasília, p. 133-160, jan./jul. 2010.

VENTURA, Miriam. Transexualidade: algumas reflexões jurídicas sobre a autonomia corporal e autodeterminação da identidade sexual. In: RIOS, Roger Raupp. (Org.). Em defesa dos direitos sexuais. Porto Alegre: Livraria do Advogado, 2007, p. 141-167.

VERGUEIRO, Viviane. Por inflexões decoloniais de corpos e identidades de gênero inconformes: uma análise autoetnográfica da cisgeneridade como normatividade. 2015. $244 \mathrm{f}$. Dissertação (Mestrado em Cultura e Sociedade) - Programa Multidisciplinar de Pós-Graduação em Cultura e Sociedade, Instituto de Humanidades, Artes e Ciências Professor Milton Santos, Universidade Federal da Bahia (UFBA), Salvador, 2016.

WALSH, Reubs; KRABBENDAM, Lydia. How social norms affect psychiatric approaches to gender incongruence. The Lancet Psychiatry, London, v. 4, n. 2, 2017. 
WYLLYS, Jean; KOKAY, Érica. Projeto de lei $\mathbf{n}^{\mathbf{0}} \mathbf{5 . 0 0 2}$ de 2013. Dispõe sobre o direito à identidade de gênero e altera o artigo 58 da Lei 6.015 de 1973. Disponível em: $<$ http://www.camara.gov.br/proposicoesWeb/fichadetramitacao?idProposicao=565315>. Acesso em: 10 fev. 2018. 